\title{
Relationships between sap flow and hydraulic conductivity in soybean plants*
}

\author{
S Moreshet 1, MG Huck 2, JD Hesketh 2, DB Peters 2 \\ 1 Institute of Soils and Water, ARO, Bet Dagan, Israel; \\ 2 ARS-USDA, and Department of Agronomy, University of Illinois, Urbana, Illinois, USA
}

(Received 30 March 1988; accepted 27 February 1990)

\begin{abstract}
Summary - The objective of this study was to determine the dependence of hydraulic conductance of the soybean root system upon sap flow rate and water potential gradient. Experiments were carried out in a growth cabinet on potted soybean plants grown in a glasshouse. Various proportions of the root system were removed either by cutting main root branches or by slicing through the soil mass perpendicular to the growing axis. A few leaves on each plant were covered to prevent transpiration. Their leaf water potential (LWP) was measured at the end of the experiments in a pressure chamber. Transpiration rate was estimated by weighing the pots at 30-min intervals. Hydraulic conductance of the remaining root system was calculated as the ratio of transpiration rate to the covered leaf water potential. The same plants were then detopped and their root medium was enclosed in a pressure chamber.

Sap exudation through the cut stem was proportional to the applied pneumatic pressure in all cases examined. The proportionality coefficients represent the hydraulic conductances of the root system. The conductances were linearly related to the weight of the remaining roots (diameter $<1 \mathrm{~mm}$ ). The slope of this relation represents the apparent conductivity of a root. Apparent conductivity was also estimated from the ratio of hydraulic conductance measured before detopping, to root weight. Both estimates of conductivity gave similar values.

Pneumatic pressures were applied to excised soybean leaves in a pressure chamber, and extracted sap was collected in small vials over consecutive 20-s intervals. Leaf water potential (LWP) was measured following each extraction. Sap fluxes (flow rate per unit leaf area) were proportional to the driving forces taken as the sum of applied pneumatic pressure and the average LWP. The proportionality coefficients represent the leaf conductivities. These conductivities were independent of fluxes and LWP. Measurements in cotton, avocado and grapefruit leaves confirmed this finding. As conductivities of soybean foliage and root system were both independent of flow and of the water potential gradient, we concluded that the linear flow equation was applicable to entire plant systems.
\end{abstract}

root / root conductance / leaf water potential / transpiration / cotton / avocado / citrus

Résumé - Relations entre flux d'eau et conductance hydrique chez le soja. L'étude a pour but d'établir la relation entre la conductance hydraulique du système radiculaire, le courant de sève et les gradients de potentiel hydrique.

Les expériences ont été exécutées dans des chambres de croissance sur des soja plantés en pot dans une serre. Diverses fractions du système radiculaire ont été enlevées, soit en coupant des ramifications principales, soit en tranchant au travers de la masse du sol, perpendiculairement à l'axe de croissance. Quelques feuilles sur chaque plante ont été couvertes pour empêcher leur transpiration. Leur potentiel hydrique (LWP) a été mesuré à la fin de l'expérience dans une chambre à pression. Le taux de transpiration a été estimé par pesée toutes les 30 minutes. La conductance hydraulique des racines restantes a été calculée comme étant le rapport du taux de transpiration stable sur le LWP des feuilles couvertes.

Ces mêmes plantes ont été sectionnées à la base de la tige. Leur système sol-racine a été enfermé dans une chambre à pression. Le système radiculaire a été pressurisé (fig $2 \mathrm{H}$ ) et décompressé (fig $2 B$ ) par étapes. Les taux d'exudation produits par décompression sont en meilleure relation linéaire avec la pression que ceux obtenus pendant la pressurisation (fig 3C). Le long délai entre l'application de la première étape de haute pression et l'obtention d'un taux d'exudation constant est attribué à un rétrécissement initial des racines qui rompt momentanément la continuité eau-racine. Dans chaque cas on a trouvé que l'exudation de sève à la coupure, est proportionnelle à la pression pneumatique appliquée (fig 4). Les coefficients de proportionnalité sont les conductances hydrauliques du système radiculaire. Ces dernières sont en relation linéaire (fig $5 A$ ) avec le poids des racines fines (diamètre $<1 \mathrm{~mm}$ ). La pente de la relation définit la conductivité hydraulique apparente des racines. Sa valeur est semblable à celle obtenue à partir de la conductance hydraulique mesurée avant le sectionnement des tiges. On a exercé une pression pneumatique sur des feuilles de soja excisées, puis on a récolté le liquide extrait pendant $20 \mathrm{sec}$. A la fin de chaque extraction on a

\footnotetext{
* Contribution from the Agric Res Organ, The Volcani Center, Bet Dagan, Israel, 1989 ser, No 2272-E
} 
mesuré le LWP. Le flux liquide d'exudation rapportée à l'unité de surface, est proportionnel à la somme de la pression pneumatique et du LWP moyen (fig 6). Le coefficient de proportionnalité et la conductivité foliaire (tableau l). Cette conductivité est indépendante du flux et du LWP. Des mesures faites sur des feuilles de cotonnier, d'avocadier et d'oranger confirment cette observation (fig 7).

Comme les conductivités hydrauliques du feuillage et du système radiculaire sont toutes deux indépendantes, à la fois du flux et du gradient de potentiel, il est conclu que l'équation linéaire du mouvement est appliquable à la plante entière.

racine / conductance radiculaire / potentiel hydrique / transpiration / coton / avocat / agrume

\section{INTRODUCTION}

Water enters root systems most readily through those regions which offer the least resistance to water flow (Sanderson, 1983). Yet Brouwer (1965) found that increasing transpiration rate enhanced the absorption rate of some root zones more than others. This observation might suggest that hydraulic conductance of the root system as a whole is variable, and depends upon the transpiration rate. Others have reported such a phenomenon in roots (Stoker and Weatherley, 1971; Aston and Lawlor, 1979; Jones et al, 1982).

Blizzard and Boyer (1980) demonstrated an apparent increase in root conductance as water potential dropped. Boyer (1985) argued that some of the previously reported observations did not consider the effect of non-steady-state transpiration upon their results. Boyer (1974) noted that water transport through roots showed only a slight non-linearity in comparison with that attributable to the leaves. Recently, Koide (1985) has suggested that hydraulic conductance of the system through which the transpiration streams does vary, and that the majority of the variability is located in the roots and not in the leaves.

The objective of this study was to investigate the conflicting evidence concerning constant versus variable conductances, and to examine Koide's (1985) interpretations concerning the location of the variable conductances. The present report is part of a broader study which examined the effect of removing various parts of the root system of soybean plants on transpiration and conductances. Most of the methods used have been reported elsewhere (Moreshet et al, 1988) and only those which are relevant will be described here.

\section{MATERIALS AND METHODS}

\section{Growth conditions}

Soybean (Glycine max (L) Merr var Williams) seedlings were pruned to develop exactly 4 main lateral roots by cutting the taproot and removing all other branching roots. The seedlings were inoculated with Rhizobia spp and grown in 81 plastic pots filled with $4.5 \mathrm{~kg}$ (dry basis) of a steam sterilized soil:peat moss:Perlite (5:1:1 by vol) mixture. The soil component was taken from the surface $(20 \mathrm{~cm})$ of a Flanagan (Aguic Arguidoll) silt loam near Urbana, IL (USA). Prior to planting, pots were irrigated to field capacity with a nutrient solution (Blizzard and Boyer, 1980). Ten plants were started in each series, with a new series initiated at 2-3 wk intervals throughout the winter of 1985-1986. The plants were grown in a heated glasshouse supplemented with $1 \mathrm{KW}$ General Electric $\mathrm{MH}$ $1000 \mathrm{BU}-4$ metal halide lamps for $13 \mathrm{~h}$ each day.

At the age of $6-8$ weeks, 8 plants per series were transferred to a growth cabinet kept at $35^{\circ} \mathrm{C}$ and $40 \%$ $\mathrm{RH}$, and with a 13-h day length. Illumination was supplied by a $1.2 \times 2.4 \mathrm{~m}^{2}$ bank of 26 General Electric Deluxe Cool White fluorescent lamps, supplemented by 4 $400 \mathrm{~W}$ incandescent lamps. Plants were placed on a rotating bench (one turn per $3 \mathrm{~min}$ ) to ensure uniformity of environmental conditions.

The amount of roots available to supply the transpiration needs of uniformly-sized shoots was varied by thinning various proportions of the root system as the plants were transferred into the growth cabinet. Roots were thinned in 2 different ways: by cutting 1, 2, or 3 main laterals ( 3 plants out of 8 ), or by radially slicing through the soil at 3 various depths ( 3 plants), keeping 2 plants as controls.

\section{Measurements}

Transpiration was measured by weighing the pots at 30-min intervals on an electronic balance (precision : \pm $0.1 \mathrm{~g}$ out of a range of $14-40 \mathrm{~g}$ water loss per $30 \mathrm{~min}$ ). Evaporation from the soil surface was prevented by covering the pots with a fitted lid sealed with duct tape. 
A pressure chamber (PMS, Corvallis, OR) was used to measure leaf xylem water potential and to exude sap from the leaf. A binocular microscope detected the first drop of sap appearing at the cut end of the petiole after pressurization.

In addition another large pressure chamber was constructed to hold an 8 I pot. The stem of each plant was severed above the cotyledonary node (see later for procedure), $30 \mathrm{~mm}$ of bark was removed from the cut end, and the cut stump was inserted through a hole in a rubber stopper, which was inserted into a larger hole in the chamber lid. The pot containing the root system was suspended from the lid and sealed inside the chamber. A Tygon tube, $1 \mathrm{~mm}$ internal diameter, was fitted to the cut end of the stem. The tube was filled with water and led to a beaker on a balance accurate to $\pm 0.01 \mathrm{~g}$. The entire procedure, from severing the stem through pressurizing the chamber, required less than $5 \mathrm{~min}$.

Upon completion of these tests, the soil was carefully washed from the root system. Roots, thinner than $1 \mathrm{~mm}$ (usually the white non-suberized ones) were collected, separating pruned roots from those still attached to the stem. In some instances, the conductivity of attached washed root systems dipping in water was estimated by resealing them into the chamber and while suspended in water repeating the pressurization process. When testing roots in water, air was vigorously bubbled into it through an aquarium-type "air stone".

\section{Measurement procedure}

\section{Transpiration}

Plants were allowed to acclimatize to growth cabinet conditions for 2 days. Pots on the turntable were weighed every $30 \mathrm{~min}$. When the rate of water loss reached steady state (usually after $3 \mathrm{~h}$ ), weights were recorded for an additional $3 \mathrm{~h}$ (designated as the prepruning transpiration rate). Various proportions of roots were then pruned as described in section $A$.

Appropriate leaves from each plant were covered with aluminium foil, the pots were irrigated and the lids sealed. Transpiration measurements were repeated similarly the next morning after turning on the lights, and finally the LWP of covered leaves was measured.

\section{Pressurized root exudation}

Over the next 2 days the soil of one plant at a time was saturated with water and allowed to drain. The leaves were removed for measuring leaf area, and the plant was detopped. The sap exuding from the cut stem was continuously collected into a beaker resting on the balance, and weight recorded at 60-s intervals. Finally, roots were washed from the soil, separated into thinned and intact components, oven dried and weighed.

\section{Pressurized leaf exudation}

Leaves were wrapped with aluminium foil and covered with a very lightly wetted polyethylene bag to minimize water loss during repeated cycles of pressure application and release. An initial value of leaf water potential (LWP) $\mathrm{BP}_{1}$ was obtained, and the pressure released. A pressure, IOP : $1.0 \pm \mathrm{BP}_{1} \mathrm{MPa}$ was applied to the chamber for $20 \mathrm{~s}$. Sap was collected starting from the first second of pressurization, in small vials filled with absorbent tissue paper, which were placed on top of the cut end of the petiole prior to each over-pressurization. Pressure was reduced and a new LWP was measured $\left(=\mathrm{BP}_{2}\right)$. The vials were weighed using an electronic balance accurate to $\pm 0.0001 \mathrm{~g}$.

This procedure was then repeated, pressurizing to the same IOP (fig 1). The pressurization/ depressurization cycles were repeated until the absolute value of LWP reached a level which was smaller than IOP by $0.2-0.3 \mathrm{MPa}$. At smaller differences, the collected sap could not be weighed accurately. The driving force $\mathrm{dP}$ (MPa) for a collected sap was computed as:

$$
d P=1 O P-\left(B P_{i}+B P_{i-1}\right) / 2
$$

\section{RESULTS}

\section{Water flow through detopped plants}

Exudation of xylem sap generally reached a steady flow rate after $\approx 30-60 \mathrm{~min}$, when hydrostatic pressure was increased in $0.1 \mathrm{MPa}$ increments from 0.1 to $0.9 \mathrm{MPa}$ (fig 2A).

The rate at which flow approached steady state at the various increasing pressures de-

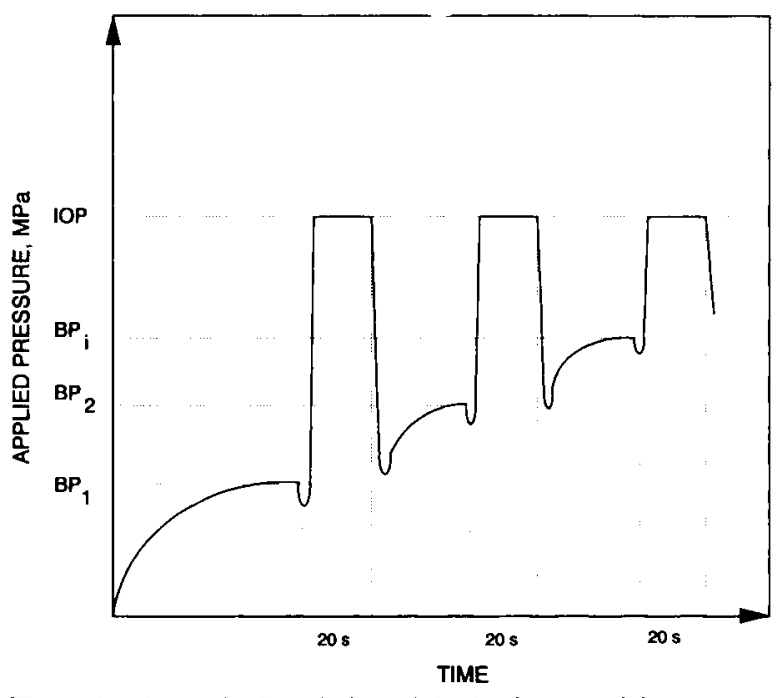

Fig 1. A schematic description of the leaf pressurizing protocol. $\mathrm{BP}_{1}$, initial leaf water potential (LWP); IOP, initial exudation pressure; $\mathrm{BP}_{2}$ and $\mathrm{BP}_{\mathrm{i}}$, LWP following previous sap exudation; 20s, time period for sap exudation. 

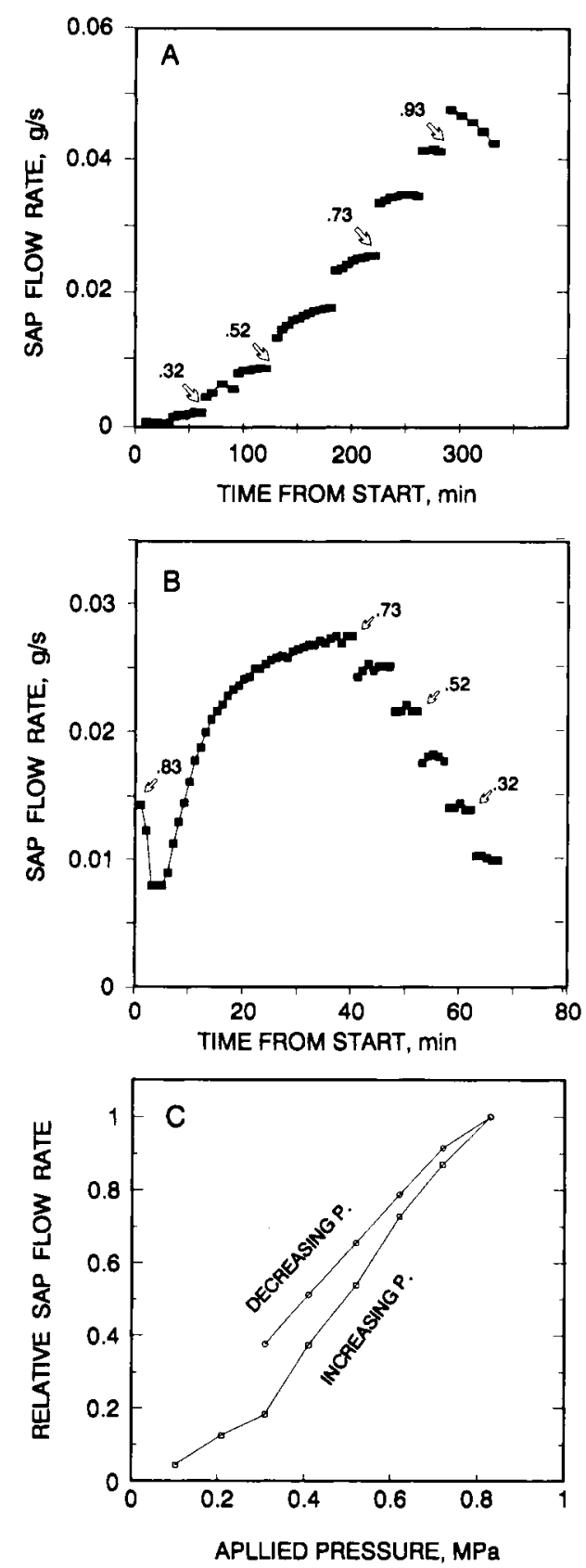

Fig 2. Xylem flow rate from a detopped soybean plant with the root system in its growing soil mixture in response to stepwise changes in pressure of $0.1 \mathrm{MPa}$ (indicated by arrows). A, Stepwise increases in pressure. B, Stepwise decreases in pressure. C, Equilibrium flow rates relative to flow at $0.83 \mathrm{MPa}$ as related to the applied pressure. Squares, increasing pressure; circles, decreasing pressure.

creased with time. After nearly $5 \mathrm{~h}$, when the applied pressure was $0.9 \mathrm{MPa}$, the xylem flow rate no longer retained a steady rate. The equilibrium flow rates related sigmoidally to applied pressure (fig 2B). The long duration of measurement ( $5 \mathrm{~h})$ may have induced changes in root properties, invalidating the use of the increasing pressure protocol for subsequent experiments.
The inverse approach is application of maximum pressure immediately after sealing the detopped plant in the chamber, followed by stepwise reductions in pressure, as illustrated in fig $2 \mathrm{~B}$. When a pressure of $0.8 \mathrm{MPa}$ was first applied, there was an immediate reduction in the flow rate, followed by a gradual increase. Equilibrium was reached in $<60 \mathrm{~min}$. Stepwise pressure reductions of $0.1 \mathrm{MPa}$ then reduced water flow to new constant rates almost immediately. The ratio of equilibrium flow rates to applied pressure sometimes deviate from linearity at pressures of 0.1 to $0.3 \mathrm{MPa}$. This observation is consistent with the findings of others (Passioura, 1980; Boyer, 1985), who noted that conductance could be assessed most easily at high flow rates when the effect of xylem solute concentrations upon flow is negligible.

The initial reduction in xylem exudation rate could result both from root compression (Huck et al, 1970; Faiz and Weatherley, 1982) and from disruption of the continuity of moisture films between root surfaces and the surrounding soil particles when the soil is not saturated. In our experiment the soil moisture was above field capacity but not saturated. Reduced contact between roots and soil water films could require some time to re-establish continuity. Figure 3 shows the change in flow rate from a detopped plant in soil at a pressure of $0.8 \mathrm{MPa}$ and after its transfer to water.

The final equilibrium flow rate was similar in both media, but the lowest rate in soil was smaller than that in water. It is assumed that the $40 \%$ difference between minimum and maximum flow

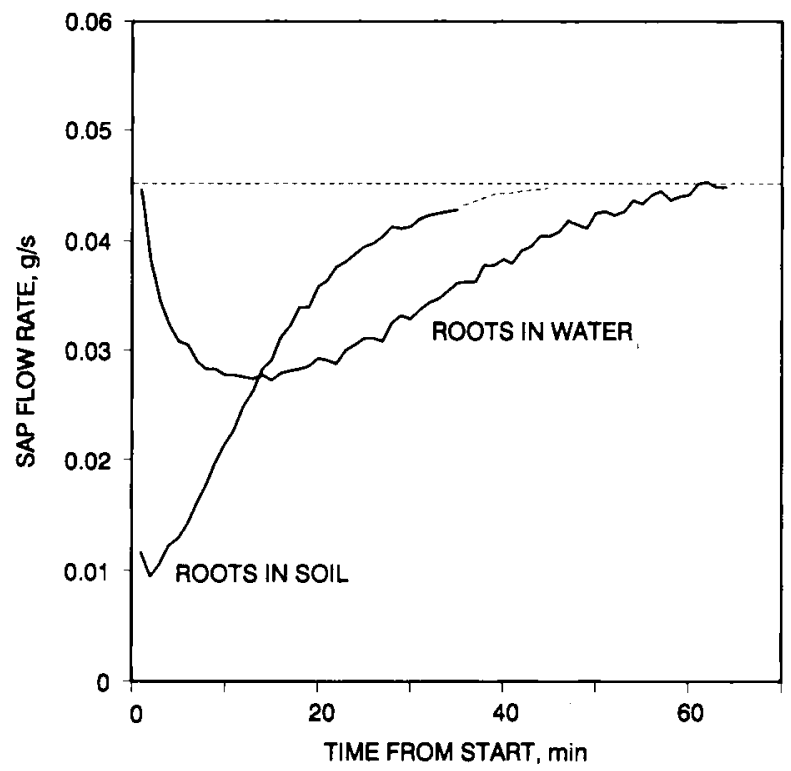

Fig 3. Xylem flow rate immediately after pressurization of a detopped soybean plant with the intact root system in its soil mixture and in aerated water after washing. $P=0.83 \mathrm{MPa}$. 
rates in water represents the drop in root conductance resulting from the change in root diameter. The deeper drop in soil resulted from the disruption of continuity of moisture films between the roots and the soil.

\section{Root system hydraulic conductance of detopped soybean plants}

The relationship between water flow rate through the root systems of detopped soybean plants and applied pressure obtained with the decreasing pressure protocol, is illustrated in figure 4 . This figure presents data from a typical series of 8 plants, one of 7 series tested.

Root systems were initially pressurized in their growing medium (non-saturated soil mixture). Penetration of water through the cut end of the prunned roots was very limited under these conditions.

The slope of the best fit lines declines roughly in proportion to the amount of the original root system which remained attached to the plant. The intercept of all lines was not significantly different from zero. At equilibrium the flow $Q(\mathrm{~g} / \mathrm{s})$ is proportional to the pressure difference, $\mathrm{dP}$ (MPa), between the applied hydrostatic pressure and atmospheric pressure. The proportionality factor, $\mathrm{K}\left(\mathrm{g} \cdot \mathrm{s}^{-1} \cdot \mathrm{MPa}^{-1}\right)$, which is the slope of the lines in figure 4 , represents the hydraulic conductance of the root system.

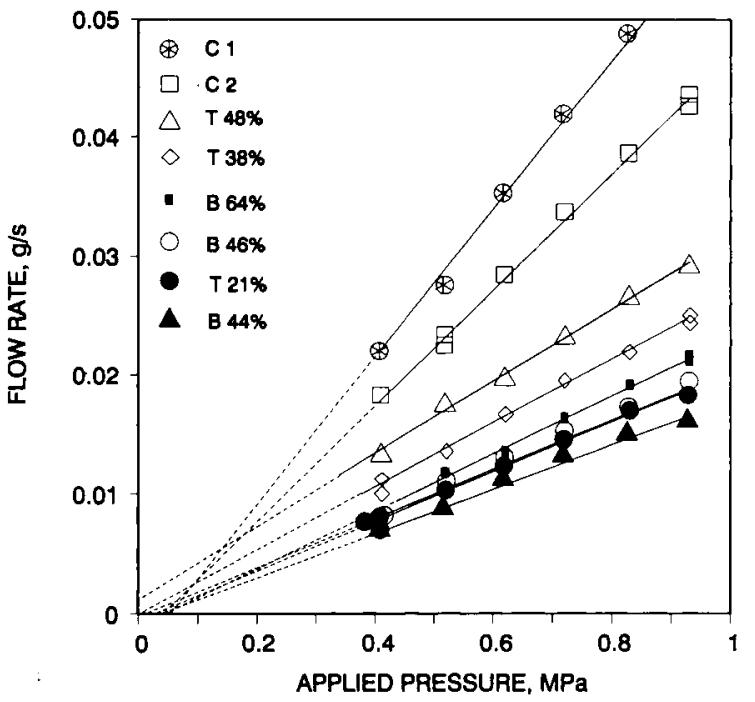

Fig 4. Pressure induced xylem flow rates from one set of eight detopped soybean plants, with the root systems in the original potting-soil mixture. $\mathrm{C} 1$ and $\mathrm{C} 2$, control plants; $\mathrm{T}$, remaining top part of the root system after radially slicing through the soil to remove the lower part of the roots; B, remaining main root branches after detaching some of the main branches with a sharp knife. The numbers are the percentage of remaining roots on a dry weight basis.
Most roots were quite uniform in diameter, and hence root dry weight should be well correlated with root length and surface area. Figure $5 \mathrm{~A}$ shows the relationship between the slopes obtained from the ratio of flow to applied pressure and root dry weight. The slope of the relationship between root hydraulic conductance and root weight is then a good measure of root conductivity. The line of best fit is : $0.0104 \mathrm{~g} \cdot \mathrm{s}^{-1}$ $\mathrm{MPa}^{-1}$ per $\mathrm{g}$ root weight. The intercept, 0.0044 , was not significantly different from zero ( \pm 0.0055 ), and $R^{2}: 0.87$. When forced through the origin the slope of the relationship was 0.0118 .

\section{Root system hydraulic conductance of intact soybean plants}

Steady state transpiration closely approximates the rate of root water uptake (Boyer, 1985). Water potential of covered non-transpiring leaves is a good estimate of the potential within the conducting vessels above the root system, but below the transpiring canopy (Begg and Turner, 1970; Meyer and Ritchie, 1980; Moreshet et al, 1990).

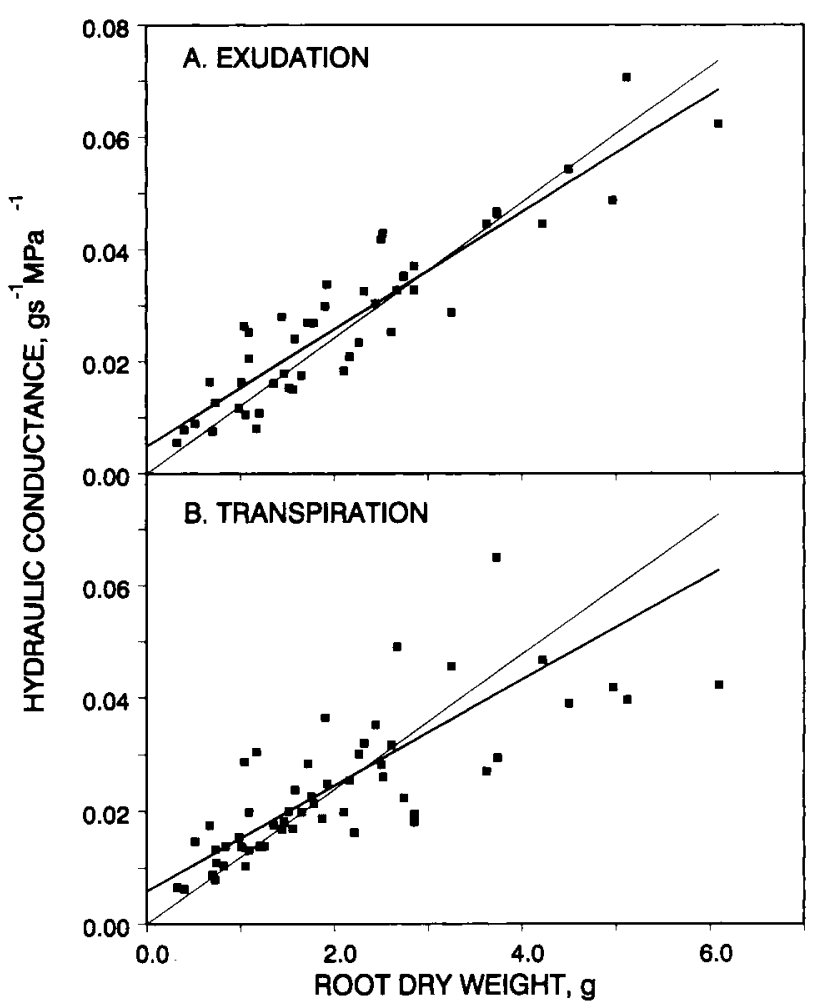

Fig 5. The relationship between soybean root system conductance and root dry weight; plants with various proportions of intact roots (see eg fig 4). A, Measured by pressurization of detopped plants. B, Calculated from measured transpiration and water potential of covered leaves. 
If soil water potential is assumed to be very close to zero (well watered soil), then root conductance may be calculated as the ratio of transpiration to the covered LWP.

Such conductances were calculated from steady state transpiration as measured in the controlled environment, and covered leaf water potential. These conductances are related to the root dry weight remaining after cutting various proportions of them as described in Materials and Methods; Transpiration (fig 5B). The slope of this line (apparent root system conductivity) is $0.0093 \mathrm{~g} \cdot \mathrm{s}^{-1} \cdot \mathrm{MPa}^{-1}$ per $\mathrm{g}$ root dry weight. The intercept, 0.0059 , was not significantly different from zero $( \pm 0.0076)$. The variability here is larger than that obtained with the pressurized roots $\left(R^{2}=0.58\right)$. This may be attributable to the small number of replicated leaves which were used for water potential measurements. Yet the magnitude of both sets of computed conductivities is quite similar. When forced through the origin, the slope of this line was 0.0119 as compared to the slope of 0.0118 obtained with the detopped root systems.

\section{Sap flow through excised leaves}

The weight of sap exuding from the cut end of the petioles, $Q$, was related to the driving force $\mathrm{dP}$ (see Materials and Methods; Pressurized leaf exudation). In all cases a linear relationship was obtained between the 2 variables (fig 6).

The possible irreversible effect of applied pressure on cell membrane properties was ex-

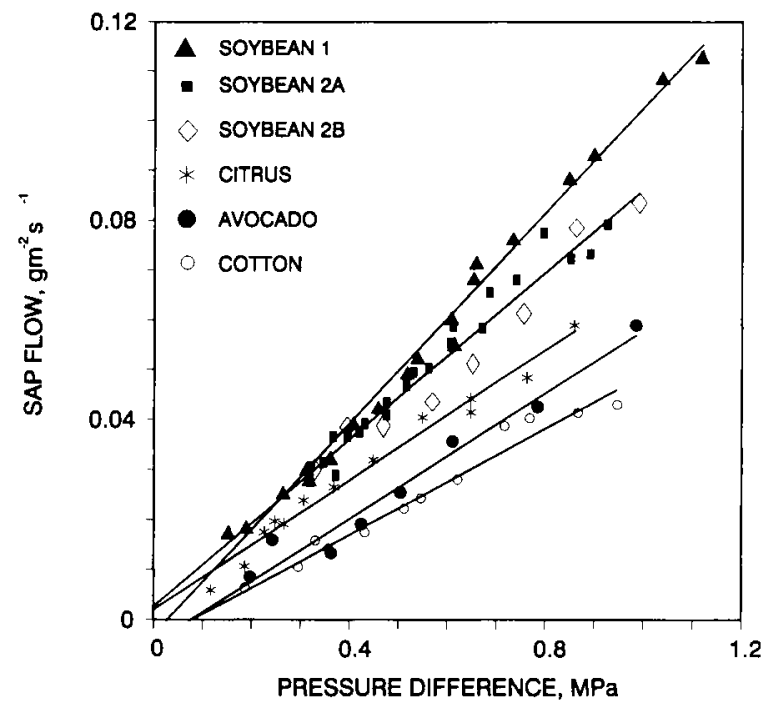

Fig 6. The dependence of exuded sap flow from soybean and 3 other crop species' leaves on the pressure difference $\mathrm{dP}$ (see text). The solid lines are calculated from the regression equations (see table I). amined in soybean leaves by relating $Q$ to $\mathrm{dP}$ at pre- and post-overnight leaf saturation (fig $6 ; 2 \mathrm{~A}$ and $2 \mathrm{~B}$, respectively). The slopes of the 2 ratios were similar (table 1). The effect was also examined by comparing leaves which were repeatedly pressurized at $1 \mathrm{MPa}$ above the absolute value of the initial LWP (fig 6; soybean 1) to leaves which started with a pressure of $0.2 \mathrm{MPa}$ above the initial LWP and ended with pressures of 1 MPa above the final LWP (fig 6; soybean 2A). The linear properties of these relationships were similar (table I). The linearity was not affected when pressurization followed the protocol which is described in fig 1 (soybean 3 and 4 in table 1).

The first two procedures were tested in other species as well. The first procedure was used in avocado (Persea americana Mill) and the latter in grapefruit (Citrus paradisi) and cotton (Gossypium hirsutum $L$ ). In all cases, the linearity of the relationships of $Q$ on $\mathrm{dP}$ was unchanged (fig 6 and table I). The $\mathrm{dP}$ at zero flux did not significantly deviate from zero (table I).

The hydraulic conductivity of a leaf (fig 6; soybean 1) was calculated for each step of the $20 \mathrm{~s}$ of sap extraction as the ratio of $\mathrm{Q}: \mathrm{dP}$. This apparent conductivity was related to the leaf water potential at each of the steps (fig 7). The conductivity did not vary greatly with LWP.

\section{DISCUSSION}

Whole plant hydraulic resistances are often computed from the ratio between exposed leaf water potential and transpiration rates (Jones et al,

Table I. Hydraulic conductivities of several soybean leaves and of leaves taken from cotton, citrus and avocado plants. Data are from same plants illustrated in fig 6 and from 2 other soybean plants. Pressurizing procedures varied as indicated in the text.

Leaf $\begin{gathered}\text { Conductivity } \\ g \cdot s^{-1} \cdot m^{-2} \cdot M P a^{-1}\end{gathered} \quad R^{2} \quad \begin{gathered}d P \pm S E \text { at } \\ \text { Zero } Q, M P a\end{gathered}$

$\begin{array}{llrrr}\text { Soybean 1 } & 0.105 & 0.99 & 0.02 \pm 0.03 \\ \text { Soybean 2A } & 0.085 & 0.96 & -0.03 \pm 0.04 \\ \text { Soybean 2B } & 0.084 & 0.96 & -0.01 \pm 0.05 \\ \text { Soybean 3 } & 0.069 & 0.97 & 0.02 \pm 0.04 \\ \text { Soybean 4 } & 0.047 & 0.99 & 0.02 \pm 0.02 \\ \text { Cotton } & 0.053 & 0.97 & 0.08 \pm 0.05 \\ \text { Citrus } & 0.064 & 0.98 & -0.04 \pm 0.03 \\ \text { Avocado } & 0.063 & 0.96 & 0.075 \pm 0.06\end{array}$




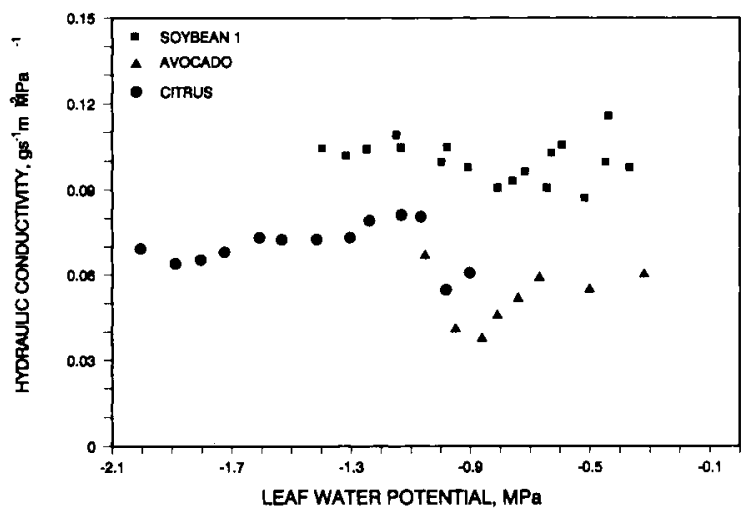

Fig 7. The dependence of the hydraulic conductance on the measured leaf water potential developed after sap exudation.

1982; Abdul-Jabbar et al, 1984; Koide, 1985; Cohen et al, 1987). The meaning and interpretation of such resistance values can be controversial. Whole-plant hydraulic resistance values have been reported as dependent upon transpiration (Jones et al, 1982; Abdul-Jabbar et al, 1984; Koide, 1985).

When measured as vapour loss, transpiration rate does not necessarily represent the sap flow in the plant. There may be a lag between uptake and loss rates, depending upon the amount of internal water storage capacity and the rate at which water can be added to or withdrawn from this internal capacitance. A large storage capacity (eg that reported in Scots pine by Waring et al, 1979) may cause such a lag. The smaller internal water storage capacity of citrus trees (Cohen et al, 1981) is not sufficient to cause a lag between water uptake and loss rates.

Soybean plants are assumed to have a relatively high storage and hence changes in water uptake lag behind changes in transpiration (Jones et al, 1982). Relating the rate of water loss from soybean plants to leaf water potential thus cannot supply a true hydraulic resistance value when measured under transient conditions. Does the relationship between steady state transpiration and leaf water potential represent the true constant hydraulic conductance? This can be validated by comparison with independent measurements of conductance like those obtained from measuring water potentials of a recovering non-transpiring stressed plant (Boyer, 1971) or from pressurization of detopped plants.

The limitation of the latter method is that it estimates the root system contribution to conductance. On the other hand, when LWP is measured in exposed leaves of a plant which is transpiring under steady state conditions, a measure of whole plant resistance can be obtained. By measuring LWP on a covered leaf, in which transpiration is blocked while the other leaves are transpiring, one can obtain an independent estimate of root system conductance (Meyer and Ritchie, 1980). When this method is used under steady state transpiration conditions (Moreshet et al, 1987) or in trees with a small storage (Moreshet et al, 1988), a true root system hydraulic conductance may be calculated and compared with the pressurization method.

The technique of pressurizing detopped plants has been questioned by several workers (Salim and Pitman, 1984; Koide, 1985). They suggested that water may be transported upwards through the intercellular spaces and the walls of the cortex in addition to the common pathways of transpired water. We assume that this does not hold in our soybean plants which had a significant amount of secondary growth in the older parts of the root system. Extensive secondary growth in the upper portion of the taproot and the older secondary roots cause disruption of the epidermis and the cortex (Lersten and Carlson, 1987). This disrupts continuity between the cortex air spaces of the younger roots and the stem.

The values for root system hydraulic conductance obtained from measuring steady state transpiration (fig 5B) are based upon the assumption that a potential difference exists between the covered leaf and the wet soil to serve as a driving force. This may not be valid if a threshold potential in the root develops before the water begins moving through the xylem (Passioura and Munns, 1984; Moreshet and Huck, 1990). It may, however, be possible to ignore this potential since our results show that apparent root conductivity values obtained from transpiration measurements are quite similar to those obtained from pressurization of detopped plants. The similarity of results from these 2 independent methods of measurement implies that the conductance measurements were applicable and that conductance is constant. This is in agreement with other reports in the literature showing constancy of root conductance (MOreshet et al, 1988) and of whole plants (Passioura and Munns, 1984; Cohen et al, 1987; Moreshet et $a l, 1990)$.

Many workers have shown that the axial resistances, although important, are small relative to radial resistances in roots (Moreshet and Huck, 1990). This is mainly due to the involve- 
ment of cell membranes in the flow process in both roots and leaves. Hence axial resistances in stems and petioles are expected to be small and may be ignored in a discussion of the flow and potential dependency of conductance.

We examined the constancy of conductances in the leaves of soybean plants as well as in leaves of some other species (fig 6; table 1). Conductance was independent of flow. This agrees with Koide's results (1985), which show constant conductances in leaves when sap flow is induced by pressure. Cell membranes, as part of the symplastic pathway, may be the major barrier for pressure-induced sap flow (Tyree and Cheung, 1977). This makes sense when dealing with an excised leaf which has limited apoplasmic water resources. Yet it seems likely that transpiring water uses the same pathway since conductance of excised transpiring leaves was not different from conductance of leaves with pressure-induced sap flow (Koide, 1985).

Since conductance is computed from both flow and water potential difference measurements, it may be dependent upon both. The data presented above show that leaf conductance is not flow dependent. Our results also suggest that leaf hydraulic conductance was largely independent of leaf water potential (fig 7). This conclusion requires independent validation, since leaf water potential is part of the driving force used to compute the conductance.

\section{CONCLUSION}

In conclusion, we suggest that hydraulic conductances of the major barriers to water flow in the soybean plant are not flow dependent. This conclusion was drawn from measurements in detached leaves and was confirmed in intact root systems by 2 independent methods of measurement.

\section{REFERENCES}

Abdul-Jabbar AS, Lugg DG, Sammis TW, Gay LW (1984) A field study of plant resistance to water flow in alfalfa. Agron J 76, 765-769

Aston MJ, Lawlor DW (1979) The relationship between transpiration, root water uptake, and leaf water potential. J Exp Bot 30, 169-181

Begg JE, Turner NC (1970) Water potential gradients in field tobacco. Plant Physiol 46, 343-346

Blizzard WE, Boyer JS (1980) Comparative resistance of the soil and the plant to water transport. Plant Physiol 66, 809-814
Boyer JS (1971) Resistances to water transport in soybean, bean and sunflower. Crop Sci 11, 403-407

Boyer JS (1974) Water transport in plants: mechanism of apparent changes in resistance during absorption. Planta 117, 187-207

Boyer JS (1985) Water transport. Ann Rev Plant Physiol 36, 473-516

Brouwer R (1965) Water movement across the root. In: Symp Soc Exp Biol 19: The State and Movement of Water in Living Organisms. Cambridge Univ Press, Cambridge, UK, 131-149

Cohen Y, Fuchs M, Green GC (1981) Improvement of the heat pulse method for determining sap flow in trees. Plant Cell Environ 4, 391-397

Cohen Y, Moreshet S, Fuchs M (1987) Changes in hydraulic conductance of citrus trees following a reduction in wetted soil volume. Plant Cell Environ 10, 53-57

Faiz SMA, Weatherley PE (1982) Root contraction in transpiring plants. New Phytol 92, 333-343

Huck MG, Klepper B, Taylor HM (1970) Diurnal variation in root diameter. Plant Physiol 45, 529-530

Jones JW, Zur B, Boote KJ, Hammond LC (1982) Plant resistance to water flow in field soybean: I. Non-limiting soil moisture. Agron J 74, 92-98

Koide $R$ (1985) The nature and location of variable hydraulic resistance in Helianthus annuus $L$ (sunflower). J Exp Bot 170, 1430-1440

Lersten NR, Carlson JB (1987) Vegetative morphology. In: Soybean: Improvement, Production and Uses (Wilcox JR, ed) Agronomy 16, 2nd edn, ch 3, 49-94

Meyer WS, Ritchie JT (1980) Water status of cotton as related to taproot length. Agron J 72, 577-580

Moreshet S, Huck MG (1990) Dynamics of water permeability. In: Plant Root - the Hidden Half (Waisel Y, Kafkafi U, Eshel A, eds) Marcel Dekker Inc, NY (in press)

Moreshet S, Huck MG, Hesketh JD, Peters DB (1987) Measuring the hydraulic conductance of soybean root systems. In: Proc Int Conf on Measurement of Soil and Plant Water Status. Plants. (Hanks RJ, Brown RW, eds) Utah State Univ Logan, UT 2, 221 227

Moreshet S, Allen LH Jr, Cohen Y, Fuchs M, Jones JW, Bravdo B (1988) Improving Irrigation and Radiation Efficiency of Citrus Orchards by Partial Irrigation and By Canopy and Root Size Control. Final report, BARD project I-615-83, BARD, Bet-Dagan, Israel, 1-162

Moreshet S, Cohen Y, Green GC, Fuchs M (1990) Partitioning of hydraulic conductances within mature orange trees. J Exp Bot 40 (in press)

Passioura JB (1980) The transport of water from soil to shoot in wheat seedlings. J Exp Bot 31, 333-345

Passioura JB, Munns R (1984) Hydraulic resistance of plants. II. Effect of rooting medium, and time of day, in barley and lupin. Aus J Plant Physiol 11, 341-350 
Salim M, Pitman MG (1984) Pressure-induced water and solute flow through plant roots. $J$ Exp Bot 35 , 869-881

Sanderson J (1983) Water uptake by different regions of the barley root. Pathways of radial flow in relation to development of the endodermis. $J$ Exp Bot 34, 240-253

Stoker R, Weatherley PE (1971) The influence of the root system on the relationship between the rate of transpiration and depression of leaf water potential. New Phytol 70, 547-554

Tyree MT, Cheung YNS (1977) Resistance to water flow in Fagus grandifolia leaves. Can $J$ Bot 55, 2591-2599

Waring RH, Whitehead D, Jarvis PG (1979) The contribution of stored water to transpiration in scots pine. Plant Cell Environ 2, 309-317 